\title{
Within-subject comparison of the psychopharmacological profiles of oral oxycodone and oral morphine in non-drug-abusing volunteers
}

\author{
James P. Zacny and Stephanie A. Lichtor \\ Department of Anesthesia \& Critical Care MC4028, The University of Chicago, 5841 S. Maryland \\ Avenue, Chicago, IL 60637, USA
}

\begin{abstract}
Rationale-Nonmedical use and abuse of prescription opioids is a significant problem in the USA. Little attention has been paid to assessing the relative psychopharmacological profile (including abuse liability-related effects) of specific prescription opioids.
\end{abstract}

Objectives-The aim of this study is to directly compare the psychopharmacological profile of two oral opioids within the same subject.

Methods-A randomized, placebo-controlled, crossover study was done in which 20 non-drugabusing volunteers ingested 10 and $20 \mathrm{mg}$ of oxycodone, 30 and $60 \mathrm{mg}$ of morphine, and placebo in separate sessions. Drug doses were equated on an objective measure of opiate effects: miosis. Subjective, psychomotor, reinforcing, and physiological effects of the opioids were assessed.

Results-In general, the two opioids at equimiotic doses produced similar prototypic opiate-like effects and psychomotor impairment of similar magnitude. However, several effects were found only with $20 \mathrm{mg}$ oxycodone. Both drugs produced abuse liability-related subjective effects but also dysphoric effects, particularly with $60 \mathrm{mg}$ morphine. Neither drug at either dose functioned as a reinforcer, as measured by the Multiple Choice Procedure. Relative potency ratios indicated an average oxycodone:morphine ratio of 1:3.

Conclusions-The psychopharmacological profile of oxycodone and morphine at equimiotic doses had many similarities; however, differences were found in producing abuse liability-related and dysphoric effects. In the medical community, it is commonly accepted that oral oxycodone is 1.5 to 2 times as potent as oral morphine in producing analgesia; using this ratio, although patients may experience similar degrees of pain relief, those receiving oxycodone may be experiencing stronger and potentially different psychopharmacological effects.

\section{Keywords}

Opioid; Oxycodone; Morphine; Abuse liability; Prescription; Human

\section{Introduction}

Nonmedical use and abuse of prescription opioids has increased markedly over the last decade in the USA (e.g., Zacny et al. 2003; Gilson et al. 2004; Cicero et al. 2005). The significance of the problem has been demonstrated by results from national epidemiological surveys addressing different facets of nonmedical use and abuse of prescription opioids (e.g., 
prevalence rates of nonmedical use in people aged 12 and older, prevalence rates in secondary school students, health consequences of nonmedical use, number of treatment admissions; Substance Abuse and Mental Health Administration 2006a,b,c; Johnston et al. 2007) and is of concern to regulatory, pain relief advocacy, law enforcement, and drug abuse organizations (e.g., Passik et al. 2006; Katz et al. 2007). There are many questions that remain to be addressed regarding the nonmedical use and abuse of prescription opioids (see Compton and Volkow 2006). For example, little attention has been paid to assessing the relative psychopharmacological profile of specific prescription opioids. An important aspect of that profile would include abuse liability-related effects. Such data are important, as there have been no studies that we are aware of directly comparing one opioid to another within the same subject to adequately determine whether different strong (i.e., high analgesic efficacy) oral opioids have identical abuse liability-related profiles (see Zacny et al. 2003, p.225).

Zacny and Gutierrez (2003) examined the subjective, psychomotor, and physiological effects of oral oxycodone $(0,10,20$, and $30 \mathrm{mg})$ in non-drug-abusing volunteers, and in a preliminary attempt to address the relative abuse liability of oxycodone to another opioid, they compared one oxycodone dose to a putatively equianalgesic dose of morphine, considered to be a "gold standard" mu opioid. Oxycodone generated a number of prototypic opiate effects, including abuse liability-related subjective effects (defined as those measures that are considered pleasant in nature and have apparent face validity in predicting abuse liability), in a dose-related manner, including ratings of drug liking and "want to take drug again." Forty mg of morphine, a dose that was thought to be equianalgesic to that of $30 \mathrm{mg}$ of oxycodone, did not generate the same quantity or magnitude of subjective or psychomotor-impairing effects as did 30 or even $20 \mathrm{mg}$ of oxycodone. One possibility for the differences is that perhaps oral oxycodone has a different psychopharmacological profile than oral morphine. However, only one dose of morphine was tested; furthermore, the $30 \mathrm{mg}$ oxycodone dose (and the $20 \mathrm{mg}$ dose) produced a statistically significantly greater degree of miosis than $40 \mathrm{mg}$ morphine, indicating the dosages were not equipotent on a prototypic physiological response to opioids (e.g., Fedder et al. 1984; Martin 1984; Benziger et al. 1997). The comparison of $40 \mathrm{mg}$ of morphine to $30 \mathrm{mg}$ of oxycodone was based on a morphine/oxycodone analgesic potency ratio of 1.3:1 reported in a study on cancer-pain patients in severe pain (Kalso and Vainio 1990), but there are other reported analgesic potency ratios (e.g., Foley 1985; Curtis et al. 1999). This leaves open the possibility that morphine would generate a similar profile of psychopharmacological effects to that of oxycodone if higher morphine doses were tested (that were equipotent to oxycodone on some objective measure).

To investigate this possibility, and because of the need for research comparing the relative psychopharmacological effects of prescription opioids, we conducted the following study. Using a crossover design, we directly compared two doses of oxycodone (10 and $20 \mathrm{mg}$ ) with two doses of morphine ( 30 and $60 \mathrm{mg}$ ), respectively, equating doses on miosis-an objective biological index of opioid action and a standard measure used in abuse liability testing (Jasinski 1977; Bigelow 1991). Miosis is correlated with plasma opioid concentration, ability to suppress abstinence, incidence of side effects, and intensity of euphoria (e.g., Fraser et al. 1954; Jasinski 1977; Lalovic et al. 2006). The degree to which it correlates with analgesia has been termed as "inconsistent" (Fraser et al. 1954, p. 450). Dependent measures were subjective, reinforcing, psychomotor/cognitive, and physiological effects. In addition, we conducted relative potency analyses of the two oral opioids.

\section{Materials and methods}

Subject inclusion and exclusion criteria, procedural aspects of the study, and dependent measures are described in detail in a study previously published in this journal (Zacny and Gutierrez 2003) and therefore will be briefly described below. 


\section{Subjects}

The local Institutional Review Board approved the study. Before participating, volunteers signed an informed-consent form that described the study in detail. Before the first session, subjects were interviewed for assessment of their psychiatric and medical status and to screen out those with contraindications to participation in the study. Subjects attended an orientation session in which they practiced mood and psychomotor tests to acclimate them to the tests and to minimize any practice effects on psychomotor testing during experimental sessions. Following completion of the study, participants were debriefed and received payment.

All volunteers reported prior recreational drug use, but none had histories indicative of substance abuse or dependence (American Psychiatric Association 2000). Six volunteers withdrew from the study after completing at least one session, and their demographic data are not included below. Two withdrew after the first session because of drug side effectsexcessive nausea and vomiting; one after receiving the highest dose of morphine and the other after receiving the lowest dose of oxycodone. The remaining four withdrew or were withdrawn for reasons unrelated to the study drugs. Twenty healthy volunteers, 10 men and 10 women, with a mean age $( \pm \mathrm{SD})$ of $25.7 \pm 6.0$ and body mass index of $23.8 \pm 2.0$, completed the study. One subject's drug history is not included, as the data were inadvertently lost. Their selfreported number of alcohol drinks consumed per week (over the last 30 days) averaged 3.9 \pm 3.1 . Six reported smoking tobacco cigarettes (none exceeding three per day). Four volunteers reported using marijuana (no more than 2.5 joints per week) in the last 30 days. One subject reported using lysergic acid diethylamide (LSD) once in the last 30 days. Regarding lifetime nonmedical drug use, four volunteers reported use of hallucinogens (LSD, psilocybin), two volunteers reported use of club drugs (ecstasy), three volunteers reported use of stimulants (cocaine/crack, over-the-counter diet pills), and 13 reported use of cannabinoids. With the exception of cannabinoids, lifetime drug use of any one of these drugs was less than 50 times in any one person. One volunteer reported recreational use of hydrocodone (Vicodin or Lortab); one volunteer reported recreational use of opium (smoked). Lifetime recreational use of these opiates was less than ten times. Thirteen volunteers reported having been prescribed opiates (reported as Tylenol-3/Codeine, Vicodin or Lortab, Percocet or Percodan, and "opioids not listed above"). The number of times a prescribed opiate was used by a person in this study did not exceed 50.

\section{Experimental design and drugs}

A double-blind, randomized, placebo-controlled crossover study was conducted. In the consent form, subjects were informed that the oral drugs to be used in the study were nonexperimental and approved by the Food and Drug Administration (FDA) and belonged to one or more of the following drug classes: sedative/tranquilizer, stimulant, opiate, nonprescription pain relievers, or placebo. Participants ingested $90 \mathrm{ml}$ of water with three \#00 capsules containing 10 or $20 \mathrm{mg}$ of oxycodone hydrochloride (OXYIR ${ }^{\circledR}$ immediate-release oral tablets, Purdue Pharma) or 30 or $60 \mathrm{mg}$ of morphine sulfate (MSIR ${ }^{\circledR}$ immediate-release oral tablets, Purdue Frederick) or placebo (lactose). The lower doses of both the drugs are in the therapeutic range that would be prescribed to patients experiencing moderate to moderately severe pain. The higher doses would be considered "supra-therapeutic" to patients who were relatively opiatenaïve but have been tested safely before in healthy volunteer studies (Petry et al. 1998; Zacny and Gutierrez 2003). Based on previous studies conducted in our laboratory, the dose of morphine estimated to produce an equivalent degree of miosis as $20 \mathrm{mg}$ oxycodone was 52.5 $\mathrm{mg}$. Thirty $\mathrm{mg}$ of morphine was available in tablet form, so we chose to compare 10 and 20 $\mathrm{mg}$ oxycodone to 30 and $60 \mathrm{mg}$ morphine. A preliminary analysis of the miotic effects of oxycodone and morphine on the first six subjects to run through the protocol indicated that the corresponding doses did produce the same degree of miosis. 


\section{Experimental sessions}

Sessions were conducted in a departmental laboratory and took place from approximately 0845 to 1430 , with at least 6 days between each of the six sessions. Subjects were instructed not to eat food or drink nonclear liquids for $4 \mathrm{~h}$, not to drink clear liquids for $2 \mathrm{~h}$, and not to use any drugs (including alcohol, marijuana, over-the-counter drugs, and prescription drugs, but excluding normal amounts of caffeine and nicotine) $24 \mathrm{~h}$ prior to sessions. A urine toxicology screening was conducted prior to the start of each session for all participants and tested for the presence of amphetamines, barbiturates, benzodiazepines, cocaine and the metabolite benzoylecgonine, opiates, and phencyclidine (QuikScreen ${ }^{\circledR}$, Syntron Bioresearch, Carlsbad, CA). One potential subject tested positive for amphetamines during the orientation session and was excluded from further participation. Pregnancy screening was required for all female participants prior to each session. Each participant's breath was assessed for the presence of alcohol using a breath alcohol analyzer. During sessions, participants remained in a semirecumbent position in a hospital bed.

For the first five sessions, baseline measurements were taken of the participants' mood, psychomotor, and physiological status (see below). Subjects, under the supervision of an anesthetist, were told at the time of capsule ingestion: "The capsules you are about to ingest may or may not contain a drug." For 300 min after capsule ingestion, mood, psychomotor/ cognitive performance, and physiological measures were assessed at prescribed time points. After the session ended, subjects were required to be able to ambulate, have vital signs within $20 \%$ of their baseline values, and receive approval for release by the anesthetist. Subjects were also given questionnaires to fill out $24 \mathrm{~h}$ after the session to be brought back for the following session. Both the technician and anesthetist were blind to the drug being administered during each session but not to the drugs used in the study.

For the sixth session ("Lottery Session"), participants were presented with a bowl containing all of the choices they had made on a Multiple Choice Procedure Form (see below) $24 \mathrm{~h}$ after the first five sessions on slips of paper. The participant randomly selected a slip from the bowl. If a drug was selected, then baseline measurements were taken of the participant's vital signs, and the participant was administered the capsules containing the drug selected in the same manner as in the first five sessions. Vital signs were monitored throughout the session, but no other testing occurred. The anesthetist was not blind to the drug administered during this session. If a monetary amount was selected, no tests were conducted, and vital signs were not monitored. Otherwise, the Lottery Session ran exactly as all other experimental sessions.

Following all sessions, participants were given a snack and then transported home via a livery service with instructions not to engage in certain activities for the following $12 \mathrm{~h}$ (e.g., cooking, operating machinery, drinking alcohol).

\section{Dependent measures}

The following tests were completed before capsule ingestion (baseline), as well as at fixed time points thereafter (at 60, 120, 180, 240, and 300 min unless otherwise noted).

Subjective effects-Subjective effects were measured by five forms: a computerized, short form of the Addiction Research Center Inventory (ARCI; Haertzen 1966; Martin et al. 1971), a locally developed 12-item opiate adjective rating scale (OARS) derived from two questionnaires sensitive to the somatic and subjective effects of opioids (Fraser et al. 1961; Preston et al. 1989), a locally developed 28-item visual analog scale (VAS), a Drug Effect/ Drug Liking/Take Again (DEL/TA) questionnaire, and a locally developed 20 -item postsession sequelae questionnaire (PSQ) that assessed residual effects of the drug that subjects were asked to fill out $24 \mathrm{~h}$ after the session. The VAS and DEL/TA questionnaire were 
administered at 15, 30, 90, 150,210, and 270 min after capsule ingestion, in addition to the time points listed above. The DEL/TA questionnaire assessed the extent to which subjects currently felt a drug effect on a scale of 1 ("I feel no effect from it at all") to 5 ("I feel a very strong effect"); assessed drug liking and disliking on a 100-mm line ( $0 \mathrm{~mm}=$ dislike a lot; 50 $\mathrm{mm}=$ neutral; $100 \mathrm{~mm}=$ like a lot); and assessed how much subjects "would want to take the drug you received today again on another session, if given the opportunity" on a 100-mm line [0 mm=definitely would not; $50 \mathrm{~mm}=$ neutral (don't care); $100 \mathrm{~mm}=$ definitely would]. At the end of each session and $24 \mathrm{~h}$ later, subjects were asked to rate overall drug liking and overall "want to take drug again" on a modified version of the DEL/TA questionnaire.

Multiple choice procedure-The reinforcing effects of each drug were assessed using a modified version of the Multiple Choice Procedure (MCP; Griffiths et al. 1993). The two-page questionnaire consisted of 39 choices to receive the drug received in a session (e.g., "Receive Drug from Session 1") versus giving up or receiving a certain amount of money (ranging from "Give up \$10" to "Receive \$10"). Participants were required to circle either drug or money for each independent choice. The reinforcing value of the drug was defined as the monetary amount (negative or positive) when the participant switched from choosing drug to choosing to receive or give up a certain amount of money (i.e., crossover point). The participant randomly selected from among his/her 195 choices ( 39 choices $\times 5$ experimental sessions), with each choice on a slip of paper at the beginning of his/her sixth session to provide intermittent reinforcement of drug vs money choices made on the previous sessions (Tancer and Johanson 2003). Subjects were instructed to complete the MCP $24 \mathrm{~h}$ following each of the first five sessions. The choice behavior was reinforced: subjects selecting a drug during the lottery session received that drug, and subjects selecting a monetary amount had that amount added to or subtracted from their participation payment and did not receive any drug during the lottery session.

Psychomotor/cognitive performance-Five tests were used in the study: an eye-hand coordination test (Nuotto and Korttila 1991), the Digit Symbol Substitution Test (DSST;

Wechsler 1958), an auditory reaction test (Nuotto and Korttila 1991), a logical reasoning test (Baddeley 1968), and a locally developed recall memory test. The DSST was administered at $15,30,90,150,210$, and $270 \mathrm{~min}$ after capsule ingestion, in addition to the time points listed above.

Physiological measures-Six measures were assessed: heart rate, blood pressure, arterial oxygen saturation, respiration rate, exophoria, and pupil size. Pupil diameter was measured by using pictures taken with a Polaroid camera with a $2 \times$ magnification. The picture was taken of the participant's right eye at least $5 \mathrm{~min}$ after the room had been darkened. Eye pictures were taken at baseline and at 30,60,120, 180, and 300 min post-capsule ingestion.

\section{Statistical analyses}

Repeated-measures analysis of variance (ANOVA) was used for statistical treatment of the data (SigmaStat, Point Richmond, CA). The primary analysis compared peak (highest value obtained), trough (lowest value obtained), or mean effects of the five drug conditions. In the majority of cases, peak analyses were done, but trough analyses were done when decreases in a measure would be indicative of a drug effect (e.g., pupil size). Only post-capsule administration values were included in the peak and trough analyses, and values were determined for each subject independent of time point. Mean effect analyses were done on those measures that were assessed only once either during or after experimental sessions. $F$ values were considered significant for $p \leq 0.05$. Tukey post hoc testing was done, comparing each of the four active drug conditions to placebo, and when appropriate, comparing one active drug condition to another. A secondary analysis measured time course of drug effects, but for the sake of brevity only a selected number of measures will be presented in the "Results" 
section. We should note that we also analyzed the data using sex as a factor, and although there were some sex $x$ drug interactions, post hoc power analyses informed us that we had insufficient power to detect sex differences. This was not surprising as we did not power the study to detect significant sex $\times$ drug interactions. Therefore the few interactions we observed could be spurious and will not be reported on in the paper.

We conducted a relative potency analysis of the two opioids. Peak, trough, and mean effects data from the 10- and 20-mg oxycodone conditions and the 30- and 60-mg morphine conditions were analyzed using Finney's (1964) method for parallel line bioassays. Specifically, data that yielded statistically significant effects (i.e., from those measures on which one or more active drug conditions differed significantly from placebo) and which were collected during the session were used in these analyses. Post-session measures were not included because they were retrospective (over the previous 24-30 h) rather than current evaluations of effects; postsession measures can therefore not be compared to within-session measures in these estimates because they differ in the time frame over which they are measuring relative potency.

Assessment of current effects in determining relative potency estimates in the present study is consistent with prior human psychopharmacology studies (see Jasinski 1977; Eissenberg et al. 1999). The analysis of parallel line bioassays is used to determine the relative potency of two compounds. This analysis was used to determine that the dose-response function did not deviate from parallelism $(p>0.05)$ and showed significant regression (the slopes of the doseresponse functions were significantly different from $0, p<0.05$ ) without preparation differences (overall effect magnitude did not differ across drugs, $p>0.05$ ).

\section{Results}

Table 1 summarizes mean peak, mean trough, or mean values $( \pm$ SEM) of subjective effects, psychomotor/cognitive performance, reinforcing effects, and physiological measures that were sensitive to one or more of the active drug conditions (relative to placebo).

\section{Subjective effects}

Addiction Research Center Inventory-All five scales of the ARCI were altered by one or more of the drug conditions (Table 1). Apart from the A and Morphine Benzedrine Group (MBG) scales, the two lower doses of oxycodone and morphine produced effects similar in magnitude to each other (although some effects did not achieve statistical significance), and the two higher doses produced greater effects that were also similar in magnitude to each other. Only the 30-mg morphine (MOR $30 \mathrm{mg}$ ) dose produced significant increases in mean peak MBG scores, relative to placebo, and the scores obtained in the 60-mg morphine (MOR 60 $\mathrm{mg}$ ) condition were significantly lower than both MOR $30 \mathrm{mg}$ and $20 \mathrm{mg}$ oxycodone (OXY $20 \mathrm{mg}$ ) and lower than that of placebo, although the difference was not significant.

Visual analog scale-Table 1 shows that there were a number of ratings that were statistically significantly increased by both OXY $20 \mathrm{mg}$ and MOR $60 \mathrm{mg}$ and that the magnitude of effects were similar. In general, these ratings were not significantly increased by $10 \mathrm{mg}$ oxycodone (OXY $10 \mathrm{mg}$ ) and MOR $30 \mathrm{mg}$, although oftentimes there was a trend for values to be higher than in the placebo condition. There were six ratings in which significant peak effects were found only with OXY $20 \mathrm{mg}$ (relative to placebo) and not with MOR $60 \mathrm{mg}$, and three of them also differed significantly from MOR $60 \mathrm{mg}$ ["drunk," "elated" (very happy), and "stimulated" (energetic)]. In cases where the highest doses of each respective drug produced significant increases, time course analyses revealed similar onset of effect on some measures (e.g., "dreamy," "heavy or sluggish feeling"), whereas in others oxycodone had a faster onset of effect (e.g., "nauseated," "high"). Because of the lack of consistency in onset of effect this will not be discussed further. 
Opiate adjective rating scale-The lower doses of OXY and MOR both significantly increased peak "carefree" ratings relative to placebo. Both doses of MOR, but neither dose of OXY, increased peak ratings of "dry mouth." Although the absolute magnitude of the increases was relatively small, MOR $60 \mathrm{mg}$ significantly increased ratings of "flushing", and OXY 20 mg significantly increased ratings of "sweating." Peak ratings of "vomiting" were not significantly increased by any dose of oxycodone or morphine, but the research technician observed four instances of vomiting, both in the OXY $20 \mathrm{mg}$ and in the MOR $60 \mathrm{mg}$ conditions.

Drug effect/drug liking/take again-Peak ratings of "feel drug effect" were significantly increased in all active drug conditions, with OXY $20 \mathrm{mg}$ and MOR $60 \mathrm{mg}$ producing similar effects and greater effects than that of OXY $10 \mathrm{mg}$ and MOR $30 \mathrm{mg}$. The greater effects of OXY $20 \mathrm{mg}$ relative to OXY $10 \mathrm{mg}$ achieved statistical significance. Figure 1a shows time course of "feel drug effect." Onset of effect was at 30 min post-ingestion for OXY $20 \mathrm{mg}$ and at $60 \mathrm{~min}$ for all other active drug conditions. OXY $20 \mathrm{mg}$ produced higher ratings than did MOR $60 \mathrm{mg}$ prior to the $180-\mathrm{min}$ time point, and then the reverse was true after $180 \mathrm{~min}$. At only one time point did the two drugs at the higher doses differ significantly from each other, and that was at 120 min post-capsule ingestion. A similar pattern of effects was noted with the lower doses as with the higher doses, but at no time point did the two drugs significantly differ.

Peak ratings of drug liking and "want to take drug again" were significantly increased relative to placebo by MOR $30 \mathrm{mg}$ and OXY $20 \mathrm{mg}$. MOR $60 \mathrm{mg}$ and OXY $10 \mathrm{mg}$ showed increases relative to placebo, but they were not statistically significant. Trough ratings of drug liking were significantly lower relative to placebo in the MOR $60 \mathrm{mg}$ and OXY $20 \mathrm{mg}$ conditions. Ratings of drug liking and "want to take drug again" $24 \mathrm{~h}$ after the session were significantly lower than placebo only in the MOR $60 \mathrm{mg}$ condition.

Post-session sequelae questionnaire-Table 1 shows that subjects reported a number of dysphoric side effects occurring in the $24 \mathrm{~h}$ following the MOR $60 \mathrm{mg}$ session (and in some cases the MOR $30 \mathrm{mg}$ session), compared to the placebo session. One and two participants reported vomiting after the OXY $10 \mathrm{mg}$ and MOR $30 \mathrm{mg}$ sessions on the PSQ, respectively. Based on ratings from the PSQ, comments made on the PSQ, and observation by the research technician, four subjects vomited after the OXY $20 \mathrm{mg}$ session, and four vomited after the MOR $60 \mathrm{mg}$ session.

\section{Multiple choice procedure}

No dose of any active drug had crossover values that were significantly higher than placebo, which would have been indicative of reinforcing effects. Crossover values in the MOR $60 \mathrm{mg}$ condition were significantly lower than that of placebo; on average, subjects were willing to give up $\$ 4.60$ from their earning to not receive the drug during the Lottery Session.

\section{Psychomotor/cognitive performance}

Performance on the DSST (number of symbols drawn and drawn correctly) was significantly impaired relative to placebo and, to a similar degree, by the two higher doses of oxycodone and morphine. OXY $20 \mathrm{mg}$ impaired performance on the logical reasoning test (number of statements answered) and on the eye-hand coordination test (seconds outside circle) relative to placebo.

\section{Physiological effects}

Heart rate, systolic and diastolic blood pressure, and respiration rate were decreased by one or more active drug conditions but were clinically nonsignificant (changes were within 20\% of placebo values). Exophoria was significantly increased by OXY $20 \mathrm{mg}$ relative to placebo. Mean trough pupil size values showed that all active drug conditions significantly differed 
from placebo values, and the effects were dose-related (e.g., pupil size was significantly smaller with OXY $20 \mathrm{mg}$ than with OXY $10 \mathrm{mg}$ ). Important to note is that pupil sizes were similar across the lower doses of the two drugs and the higher doses. Figure $1 \mathrm{~b}$ shows time course of miosis. Pupil sizes were significantly decreased with both doses of OXY at every time point starting at $30 \mathrm{~min}$ and with both doses of MOR starting at $60 \mathrm{~min}$. Pupil sizes were significantly smaller in the OXY $20 \mathrm{mg}$ condition than in the MOR $60 \mathrm{mg}$ condition at two time points (30 and $60 \mathrm{~min}$ ). The reverse held true at the $300 \mathrm{~min}$ time point in that pupil sizes were significantly smaller in the MOR $60 \mathrm{mg}$ condition than in the OXY $20 \mathrm{mg}$ condition.

\section{Relative potency analyses}

Table 2 lists relative potency estimates and 95\% confidence intervals for those variables listed in Table 1 that met criteria for a valid bioassay. Out of the 41 variables listed in Table 1 that were assessed within the session, 25 met criteria. Relative potency estimates for these variables ranged from 2.04 (VAS rating of "tingling") to 4.04 (OARS rating of "sweating"). The relative potency estimate for pupil size was not at the projected estimate of 3.0 but was 3.51. The overall geometric mean of the 25 variables was 3.14.

\section{Discussion}

In a previous study conducted in our laboratory, 20 and $30 \mathrm{mg}$ of oral oxycodone produced a greater quantity and magnitude of psychopharmacological effects, including some that were abuse liability-related, than did $40 \mathrm{mg}$ of oral morphine. However, the oxycodone doses produced greater miosis, and so the greater degree of psychopharmacological effects of oxycodone could have been due to testing doses of oxycodone that were more potent than the morphine dose tested. In the present study, we tested doses of oxycodone and morphine that produced a similar degree of miosis, and to a considerable extent, the two drugs had similar psychopharmacological profiles. Similarities between the highest doses of each respective drug were found on a number of subjective effects that are considered prototypic of mu agonist opioids in non-drug-abusing volunteers, including increases in pentobarbital-chlorpromazinealcohol group (PCAG) and LSD scores on the ARCI, "heavy or sluggish feeling" and "coasting" ('spaced out') on the VAS, and "skin itchy" on the OARS. Most effects were doserelated, but significant effects (relative to placebo) were mainly confined to the higher doses of each respective drug. Both oxycodone and morphine at the higher doses produced a similar degree of psychomotor impairment as measured by the DSST. Both doses of the study drugs increased miosis in a dose-related fashion, and degree of miosis was similar with the two lower doses of the drugs and with the two higher doses of the drugs. Such findings indicating similarity of effects are consistent with much of the extant literature comparing these two drugs. Clinical and preclinical studies have documented a number of similarities between oxycodone and morphine in analgesic effects (e.g., Bruera et al. 1998; Heiskanen et al. 2000), and preclinical studies suggest that the antinociceptive and abuse liability effects of oxycodone are mediated at the mu-opioid receptor (Beardsley et al. 2004; Lemberg et al. 2007).

There were some differences between the two opioids. OXY $20 \mathrm{mg}$ but not MOR $60 \mathrm{mg}$ increased several ratings on the VAS and increased ratings of drug liking. Certainly two of the VAS measures could be considered abuse liability-related ["elated" (very happy), "having pleasant bodily sensations"], but whether three others could be considered as such is not as clear ["drunk," "floating," "stimulated" (energetic)]. We cannot conclude that oral oxycodone produces a greater degree of abuse liability-related effects than does oral morphine, however, because MOR $30 \mathrm{mg}$ increased scores on the MBG (often described as euphoria) scale and increased ratings of "carefree" (OARS) and drug liking (DEL/TA). Also in other studies, a slightly higher dose of oral morphine $(40 \mathrm{mg}$ ) produced abuse liability-related subjective effects (Zacny et al. 2003, 2005). MOR $60 \mathrm{mg}$ in this study appeared to be largely devoid of 
positive effects [with the exception of the VAS rating of "sedated" (calm, tranquil)], and tended to have dysphoric effects not only during the session but also after the session (i.e., $24 \mathrm{~h}$ ratings of drug liking and "want to take drug again," as well as responses on the PSQ). Although all active dose conditions had mean crossover values on the MCP that were negative, the MOR $60 \mathrm{mg}$ dose was the most aversive, and it was the only drug dose in which values were significantly lower than placebo. One other study has examined the subjective effects of relatively high doses of oral morphine, along with lower doses, in healthy non-drug-abusing volunteers, and found dysphoric effects at the highest dose tested (100 mg) but not at lower doses (Petry et al. 1998). In the present study, we would tentatively conclude that on balance, OXY $20 \mathrm{mg}$ had more abuse liability-related effects and fewer aversive effects than MOR 60 $\mathrm{mg}$.

Two other differences between the two opioids are worthy of mention. Both doses of morphine and neither dose of oxycodone increased ratings of "dry mouth" on the OARS. In our previous study (Zacny and Gutierrez 2003), this side effect was also noted with morphine (40 mg) but not with any dose of oxycodone. In a meta-analysis, when clinical trials with morphine were compared to trials with oxycodone, pooled odds ratios (OR) established that "dry mouth" was less prevalent with oxycodone relative to morphine (OR, 0.56; Reid et al. 2006). In an earlier clinical report, prevalence of dry mouth was strongly associated with use of morphine, relative to non-opioids, weak opioids (kinds not specified), or no analgesics (White et al. 1989). Thus we have replicated in two laboratory studies what apparently has been found in the clinical milieu. The mechanism accounting for a greater propensity for morphine to produce increased reports of dry mouth is not known. Another potential difference between the two drugs is differences in onset of effect. On some measures where both drugs produced significant differences from placebo, oxycodone had a faster onset of effect than morphine (e.g., miosis, ratings of "feel drug effect" and "nauseated"). However, this was not found on a number of other measures, including a number of subjective effects and DSST performance. In addition, time to peak plasma concentration in pharmacokinetic studies examining oral morphine and oral oxycodone (in immediate-release form) appear to be similar for the two drugs (Poyhia et al. 1992; Mandema et al. 1996; Collins et al. 1998). There are no other studies we are aware of directly comparing immediate-release oral oxycodone to morphine, so until more studies are done on the relative pharmacological and psychopharmacological effects of these two drugs, we can only point out the differences we found as being suggestive of a quicker onset of effect with oxycodone.

We have discussed similarities between the two opioids, and we cited studies from the extant literature suggesting that oxycodone and morphine have similar analgesic effects and that certain pharmacological effects of the drugs were mediated by the mu-opioid receptor (e.g., Beardsley et al. 2004). However, we also detected some differences between oxycodone and morphine. Is there evidence in the extant literature suggesting differences between the opioids? Several clinical studies suggest potential differences in side-effect profiles between oral oxycodone and oral morphine (Kalso and Vainio 1990; Heiskanen and Kalso 1997; MucciLoRusso et al. 1998), with oxycodone producing less severe side effects than morphine. Several preclinical studies have demonstrated that the antinociceptive effects of oxycodone are mediated at the kappa-opioid receptor [Ross and Smith 1997; Nielsen et al. 2000; Ross et al. 2000 (but see also discussion of these studies by Beardsley et al. 2004)]. In a recent study, healthy volunteers were administered $15 \mathrm{mg}$ of oxycodone and $30 \mathrm{mg}$ of morphine and then subjected to different experimental pain assays to different parts of their bodies (skin, muscle, and viscera; Staahl et al. 2006). Morphine and oxycodone were equipotent in pain modulation of the skin and muscles, but oxycodone had greater analgesic effects on mechanical and thermal stimulation of the esophagus. The authors cited the latter findings as proof that the two opioids had different pharmacological profiles. Another recent study examined the subjective and reinforcing effects of heroin and a number of prescription opioids administered via the 
intravenous route in opioid-dependent volunteers (Comer et al. 2007). In this inpatient study, volunteers with a history of heroin abuse and physical dependence and maintained on four doses of oral morphine ( $30 \mathrm{mg}$, q.i.d.), were tested with five different doses of five opioids, including morphine and oxycodone. Although morphine and oxycodone at the doses tested produced subjective and reinforcing effects that were similar in magnitude, ratings of "feel bad" (VAS range, $0-100$ ) were ' 0 ' in the high-dose oxycodone condition and '12.4' in the high-dose morphine condition. The authors made the interesting comments that oxycodone "produced some of the most robust increases in positive subjective effects and no increases in ratings of bad effects," and "given that a balance of positive and negative subjective ratings is likely to influence the degree to which a drug is abused, the fact that oxycodone produced virtually no negative effects in heroin abusers is particularly concerning." These comments are consistent with our tentative conclusion that OXY $20 \mathrm{mg}$ had more abuse liability-related effects and fewer aversive effects than MOR $60 \mathrm{mg}$.

Neither drug at the doses tested functioned as reinforcers, as assessed by the MCP. The MCP was to be completed $24 \mathrm{~h}$ following each of the first five sessions, so that subjects could base their responses on their overall reaction to the drug. OXY $20 \mathrm{mg}$ increased peak liking and "want to take drug again" ratings but also generated decreased ratings of liking (dislike) relative to placebo. MOR $30 \mathrm{mg}$ increased peak liking and "want to take drug again" ratings. However, neither OXY $20 \mathrm{mg}$ nor MOR $30 \mathrm{mg}$ produced increased end-of-session or 24-h liking and "want to take drug again" ratings, and thus the failure of the MCP procedure to detect reinforcing effects of these drug doses is perhaps not surprising. The MCP was sensitive in detecting the aversive effects of MOR $60 \mathrm{mg}$ in that subjects were willing to give up some money from their earnings to not take the drug again.

The overall geometric mean of relative potency of morphine to oxycodone was 3.14. Somewhat surprisingly, although we estimated that oxycodone would be three times as potent as morphine, the miosis relative potency value was higher than the geometric mean, i.e., 3.51. This may have been due to that fact that OXY $10 \mathrm{mg}$ produced a greater degree of miosis than did MOR $30 \mathrm{mg}$, although statistically, the mean values did not differ from one another. In examining the different potency values for the other measures, many of them were either close to the geometric mean or higher.

The relative analgesic potency ratio of morphine:oxycodone has been estimated in a number of clinical studies, and the ratios differ somewhat. Relative potency ratios of oral morphine to oral oxycodone that we could find in the peer-reviewed literature were 1:1 (Glare and Walsh 1993), 1.3:1 (Kalso and Vainio 1990), 1.5:1 (Bruera et al. 1998), 1.7:1 (Heiskanen et al. 2000), 1.8:1 (Curtis et al. 1999), 2:1 (Foley 1985), and 2.2:1 (Curtis et al. 1999). There appears to be a consensus in the pain management community that oral oxycodone is 1.5 to 2 times as potent as oral morphine (see Levy 1996; Hanks et al. 2001). It appears that oral oxycodone and oral morphine have a different relative potency (i.e., closer to 3:1) when taking into account nonanalgesic pharmacodynamics (i.e., subjective and psychomotor-impairing effects). Such differences between analgesic and nonanalgesic potency ratios may have clinical implications for patients who are taking either oral morphine or oral oxycodone for pain relief. If the physician goes by an analgesic morphine:oxycodone potency ratio of 1.5-2:1, a patient on oxycodone may experience a stronger degree of subjective effects (e.g., dizzy, high, sleepy) and potentially be more apt to exhibit psychomotor impairment than on morphine while experiencing the same degree of analgesia.

The results of this study challenge the "de facto or implicit assumption that all the strong opioids are largely interchangeable with respect to abuse liability" (Zacny et al. 2003, p.225). The results may also have some bearing on why prevalence of nonmedical use of oral oxycodone is substantially greater than that of oral morphine (e.g., Substance Abuse and Mental Health 
Services Administration 2006d). Although it is highly probable that relative availability of the two oral opioids for licit use plays a substantial role in accounting for the different prevalence rates of nonmedical use and abuse (Zacny et al. 2003; Gilson et al. 2004; Dasgupta et al. 2006), our results showing different psychopharmacological profiles of oxycodone and morphine at the higher doses tested may also be a factor. Further research in polydrug abusers (preferably those with a history of abusing prescription opioids) is needed to determine if this notion has any credence (see Comer et al. 2007). Our findings also suggest that oral oxycodone might serve as a more appropriate positive control than oral morphine in future oral opioid abuse liability studies. This is only speculation as another opioid (such as hydromorphone) might produce more positive and fewer adverse effects than oxycodone, in which case that opioid should be used as the standard by which other oral psychoactive analgesic agents with unknown abuse liability are compared. There are an extensive number of relative abuse liability studies with opioids administered via the parenteral route (e.g., see Jasinski 1977); the results of the present study suggest more relative abuse liability studies should be conducted with prescription oral opioids whose nonmedical use and abuse is currently a substantial problem.

\section{Supplementary Material}

Refer to Web version on PubMed Central for supplementary material.

\section{Acknowledgements}

Research was supported in part by Grant RO1 DA08573 from the National Institute on Drug Abuse. We thank the many anesthesiology residents and nurse anesthetists for administering the drugs and monitoring the physiological status of the subjects and Karin Kirulis for screening potential subjects and conducting the structured interview.

\section{References}

American Psychiatric Association. Diagnostic and statistical manual of mental disorders DSM-IV-TR (Text Revision). American Psychiatric Association; Washington DC: 2000.

Baddeley AD. A three-minute reasoning test based on grammatical transformation. Psychon Sci 1968;10:341-342.

Beardsley PM, Aceto MD, Cook CD, Bowman ER, Newman JL, Harris LS. Discriminative stimulus, reinforcing, physical dependence, and antinociceptive effects of oxycodone in mice, rats, and rhesus monkeys. Exp Clin Psychopharmacol 2004;12:163-172. [PubMed: 15301633]

Benziger DP, Miotto J, Grandy RP, Thomas GB, Swanton RE, Fitzmartin RD. A pharmacokinetic/ pharmacodynamic study of controlled-release oxycodone. J Pain Symptom Manage 1997;13:75-82. [PubMed: 9095564]

Bigelow GE. Human drug abuse liability assessment: opioids and analgesics. Br J Addict 1991;86:16151628. [PubMed: 1686196]

Bruera E, Belzile M, Pituskin E, Fainsinger R, Darke A, Harsanyi Z, Babul N, Ford I. Randomized, double-blind, cross-over trial comparing safety and efficacy of oral controlled-release oxycodone with controlled-release morphine in patients with cancer pain. J Clin Oncol 1998;16:3222-3229. [PubMed: 9779695]

Cicero TJ, Inciardi JA, Munoz A. Trends in abuse of OxyContin ${ }^{\circledR}$ and other opioid analgesics in the United States: 2002-2004. J Pain 2005;6:662-672. [PubMed: 16202959]

Collins SL, Faura CC, Moore RA, McQuay HJ. Peak plasma concentrations after oral morphine: a systematic review. J Pain Symptom Manage 1998;16:388-402. [PubMed: 9879164]

Comer SD, Sullivan MA, Whittington RA, Vosburg SK, Kowalczyk WJ. Abuse liability of prescription opioids compared to heroin in morphine-maintained heroin abusers. Neuropsychopharmacology epub. 2007

Compton WM, Volkow ND. Major increases in opioid analgesic abuse in the United States: concerns and strategies. Drug Alcohol Depend 2006;81:103-107. [PubMed: 16023304] 
Curtis GB, Johnson GH, Clark P, Taylor R, Brown J, O’Callaghan R, Shi M, Lacouture PG. Relative potency of controlled-release oxycodone and controlled-release morphine in a postoperative pain model. Eur J Clin Pharmacol 1999;55:425-429. [PubMed: 10492054]

Dasgupta N, Kramer ED, Zalman M-A, Carino S Jr, Smith MY, Haddox JD, Wright C 4th. Association between non-medical and prescriptive usage of opioids. Drug Alcohol Depend 2006;82:135-142. [PubMed: 16236466]

Eissenberg T, Stitzer ML, Bigelow GE, Buchhalter AR, Walsh SL. Relative potency of levo-alphaacetylmethadol and methadone in humans under acute dosing conditions. J Pharmacol Exp Ther 1999;289:936-945. [PubMed: 10215673]

Fedder IL, Vlasses PH, Mojaverian P, Rocci ML Jr, Rotmensch HH, Swanson BN, Ferguson RK. Relationship of morphine-induced miosis to plasma concentration in normal subjects. J Pharm Sci 1984;73:1496-1497. [PubMed: 6502506]

Finney, DJ. Statistical method in biological assay. Hafner; New York: 1964.

Foley KM. The treatment of cancer pain. N Engl J Med 1985;313:84-95. [PubMed: 2582259]

Fraser HF, Nash TL, Vanhorn GD, Isbell H. Use of miotic effect in evaluating analgesic drugs in man. Arch Int Pharmacodyn Ther 1954;98:443-451. [PubMed: 13208336]

Fraser HF, van Horn GD, Martin WR, Wolbach AB, Isbell H. Methods for evaluating addiction liability. (a) "attitude" of opiate addicts toward opiate-like drugs, (b) a short-term "direct" addiction test. J Pharmacol Exp Ther 1961;133:371-387. [PubMed: 13701509]

Gilson AM, Ryan KM, Joranson DE, Dahl JL. A reassessment of trends in the medical use and abuse of opioid analgesics and implications for diversion control: 1997-2002. J Pain Symptom Manage 2004;28:176-188. [PubMed: 15276196]

Glare PA, Walsh TD. Dose-ranging study of oxycodone for chronic pain in advanced cancer. J Clin Oncol 1993;11:973-978. [PubMed: 8487060]

Griffiths RR, Troisi JR II, Silverman K, Mumford GK. Multiple-choice procedure: an efficient approach for investigating drug reinforcement in humans. Behav Pharmacol 1993;4:3-13. [PubMed: 11224166]

Haertzen CA. Development of scales based on patterns of drug effects, using the Addiction Research Center Inventory (ARCI). Psychol Rep 1966;18:163-194. [PubMed: 5908477]

Hanks GW, Conno F, Cherny N, Hanna M, Kalso E, McQuay HJ, Mercadante S, Meynadier J, Poulain P, Ripamonti C, Radbruch L, Casas JR, Sawe J, Twycross RG, Ventafridda V. Morphine and alternative opioids in cancer pain: the EAPC recommendations. Br J Cancer 2001;84:587-593. [PubMed: 11237376]

Heiskanen T, Kalso E. Controlled-release oxycodone and morphine in cancer related pain. Pain 1997;73:37-45. [PubMed: 9414055]

Heiskanen TE, Ruismaki PM, Seppala TA, Kalso EA. Morphine or oxycodone in cancer pain. Acta Oncol 2000;39:941-947. [PubMed: 11207001]

Jasinski, DR. Assessment of the abuse potential of morphine-like drugs (methods used in man). In: Martin, WR., editor. Drug addiction I. Springer-Verlag; Berlin: 1977. p. 197-258.

Johnston, LD.; O'Malley, PM.; Bachman, JG.; Schulenberg, JE. Monitoring the Future national results on adolescent drug use: overview of key findings, 2006. (NIH Publication No. 07-6202). National Institute on Drug Abuse; Bethesda, MD: 2007.

Kalso E, Vainio A. Morphine and oxycodone hydrochloride in the management of cancer pain. Clin Pharmacol Ther 1990;47:639-646. [PubMed: 2188774]

Katz NP, Adams EH, Benneyan JC, Birnbaum HG, Budman SH, Buzzeo RW, Carr DB, Cicero TJ, Gourlay D, Inciardi JA, Joranson DE, Kesslick J, Lande SD. Foundations of opioid risk management. Clin J Pain 2007;23:103-118. [PubMed: 17237659]

Lalovic B, Kharasch E, Hoffer C, Risler L, Liu-Chen LY, Shen DD. Pharmacokinetics and pharmacodynamics of oral oxycodone in healthy subjects: role of circulating active metabolites. Clin Pharmacol Ther 2006;79:461-479. [PubMed: 16678548]

Lemberg KK, Kontinen VK, Siiskonen AO, Viljakka KM, Yli-Kauhaluoma JT, Korpi ER, Kalso EA. Antinociception by spinal and systemic oxycodone: why does the route make a difference? In vitro and in vivo studies in rats. Anesthesiology 2007;105:801-812. [PubMed: 17006080] 
Levy MH. Pharmacologic treatment of cancer pain. N Engl J Med 1996;335:1124-1132. [PubMed: 8813044]

Mandema JW, Kaiko RF, Oshlack B, Reder RF, Stanski DR. Characterization and validation of a pharmacokinetic model for controlled-release oxycodone. Br J Pharmacol 1996;42:747-756.

Martin WR. Pharmacology of opioids. Pharmacol Rev 1984;35:283-323. [PubMed: 6144112]

Martin WR, Sloan JW, Sapira JD, Jasinski DR. Physiologic, subjective and behavioral effects of amphetamine, methamphetamine, ephedrine, phenmetrazine, and methylphenidate in man. Clin Pharmacol Ther 1971;12:245-258. [PubMed: 5554941]

Mucci-LoRusso P, Berman BS, Silberstein PT, Citron ML, Bressler L, Weinstein SM, Kaiko RF, Buckley BJ, Reder RF. Controlled-release oxycodone compared with controlled-release morphine in the treatment of cancer pain: a randomized, double-blind, parallel-group study. Eur J Pain 1998;2:239_ 249. [PubMed: 15102384]

Nielsen CK, Ross FB, Smith MT. Incomplete, asymmetric, and route-dependent cross-tolerance between oxycodone and morphine in the Dark Agouti rat. J Pharmacol Exp Ther 2000;295:91-99. [PubMed: 10991965]

Nuotto EJ, Korttila K. Evaluation of a new computerized psychomotor test battery: effects of alcohol. Pharmacol Toxicol 1991;68:360-365. [PubMed: 1946181]

Passik SD, Heit H, Kirsh KL. Reality and responsibility: a commentary on the treatment of pain and suffering in a drug-using society. J Opioid Manag 2006;2:123-127. [PubMed: 17319444]

Petry NM, Bickel WK, Huddleston J, Tzanis E, Badger GJ. A comparison of subjective, psychomotor and physiological effects of a novel muscarinic analgesic, LY297802 tartrate, and oral morphine in occasional drug users. Drug Alcohol Depend 1998;50:129-136. [PubMed: 9649964]

Poyhia R, Seppala T, Olkkola KT, Kalso E. The pharmaco-kinetics and metabolism of oxycodone after intramuscular and oral administration to healthy subjects. Br J Clin Pharmacol 1992;33:617-621. [PubMed: 1389934]

Preston KL, Bigelow GE, Bickel WK, Liebson IA. Drug discrimination in human postaddicts: agonistantagonist opioids. J Pharmacol Exp Ther 1989;250:184-196. [PubMed: 2473187]

Reid CM, Martin RM, Sterne JAC, Davies AN, Hanks GW. Oxycodone for cancer-related pain: metaanalysis of randomized controlled trials. Arch Intern Med 2006;166:837-843. [PubMed: 16636208]

Ross FB, Smith MT. The intrinsic antinociceptive effects of oxycodone appear to be kappa-opioid receptor mediated. Pain 1997;73:151-157. [PubMed: 9415500]

Ross FB, Wallis SC, Smith MT. Co-administration of sub-antinociceptive doses of oxycodone and morphine produces marked antinociceptive synergy with reduced CNS side-effects in rats. Pain 2000;84:421-428. [PubMed: 10666549]

Staahl C, Christrup LL, Andersen SD, Arendt-Nielsen L, Drewes AM. A comparative study of oxycodone and morphine in a multi-modal, tissue-differentiated experimental pain model. Pain 2006;123:2836. [PubMed: 16600508]

Substance Abuse and Mental Health Services Administration. Results from the 2005 National Survey on Drug Use and Health: National findings (Office of Applied Studies, NSDUH Series H-30, DHHS Publication No. (SMA) 06-4194). Rockville, MD: 2006a.

Substance Abuse and Mental Health Services Administration. Drug Abuse Warning Network, 2004: National Estimates of Drug-Related Emergency Department Visits. (Office of Applied Studies, DAWN Series D-28, DHHS Publication No. (SMA) 06-4143). Rockville, MD: 2006b.

Substance Abuse and Mental Health Services Administration. Treatment Episode Data Set (TEDS). Highlights - 2005. National Admissions to Substance Abuse Treatment Services. (Office of Applied Studies, DASIS Series S-36, DHHS Publication No. (SMA) 07-4229). Rockville, MD: 2006c.

Substance Abuse and Mental Health Services Administration. 2005 National Survey on Drug Use \& Health Detail Tables. 2006d [accessed July 3, 2007]. http://www.oas.samhsa.gov/NSDUH/2k5nsduh/tabs/Sect1peTabs128to132.pdf

Tancer M, Johanson CE. Reinforcing, subjective, and physiological effects of MDMA in humans: a comparison with d-amphetamine and mCPP. Drug Alcohol Depend 2003;72:33-44. [PubMed: 14563541]

Wechsler, D. The measurement and appraisal of adult intelligence. Williams and Wilkins; Baltimore: 1958. 
White ID, Hoskin PJ, Hanks GW, Bliss JM. Morphine and dryness of mouth. Brit Med J 1989;298:12221223. [PubMed: 2473815]

Zacny JP, Gutierrez S. Characterizing the subjective, psychomotor, and physiological effects of oral oxycodone in non-drug-abusing volunteers. Psychopharmacology (Berl) 2003;170:242-254. [PubMed: 12955305]

Zacny J, Bigelow G, Compton P, Foley K, Iguchi M, Sannerud C. College on problems of drug dependence taskforce on prescription opioid non-medical use and abuse: position statement. Drug Alcohol Depend 2003;69:215-232. [PubMed: 12633908]

Zacny JP, Gutierrez S, Bolbolan SA. Profiling the subjective, psychomotor, and physiological effects of a hydrocodone/acetaminophen product in recreational drug users. Drug Alcohol Depend 2005;78:243-252. [PubMed: 15893155] 
a

Feel Drug Effect

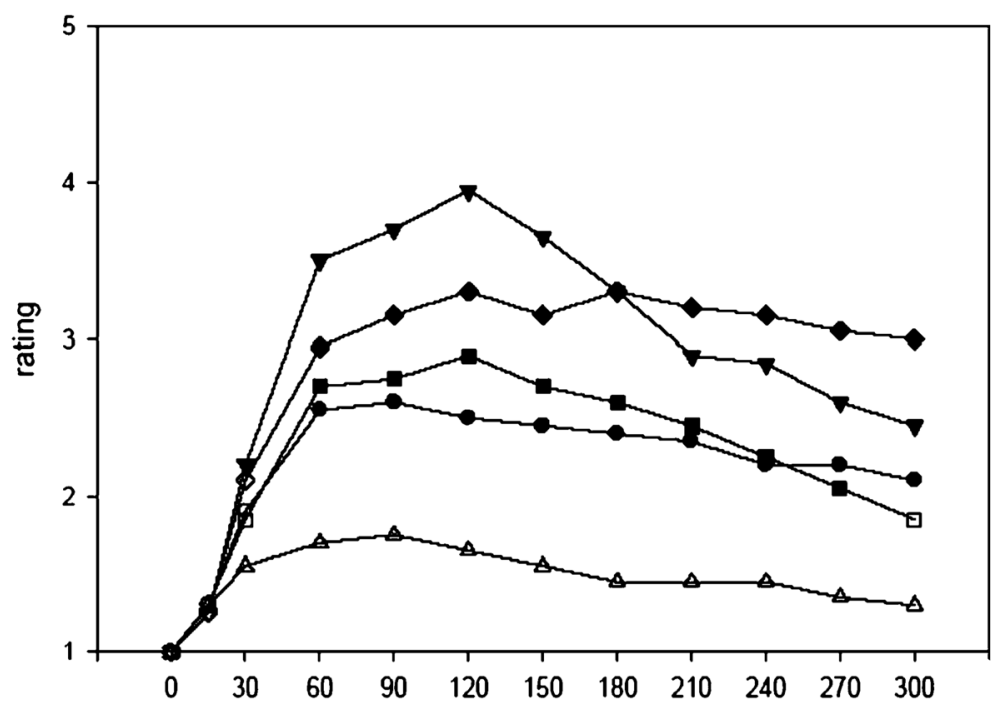

b

Pupil Size

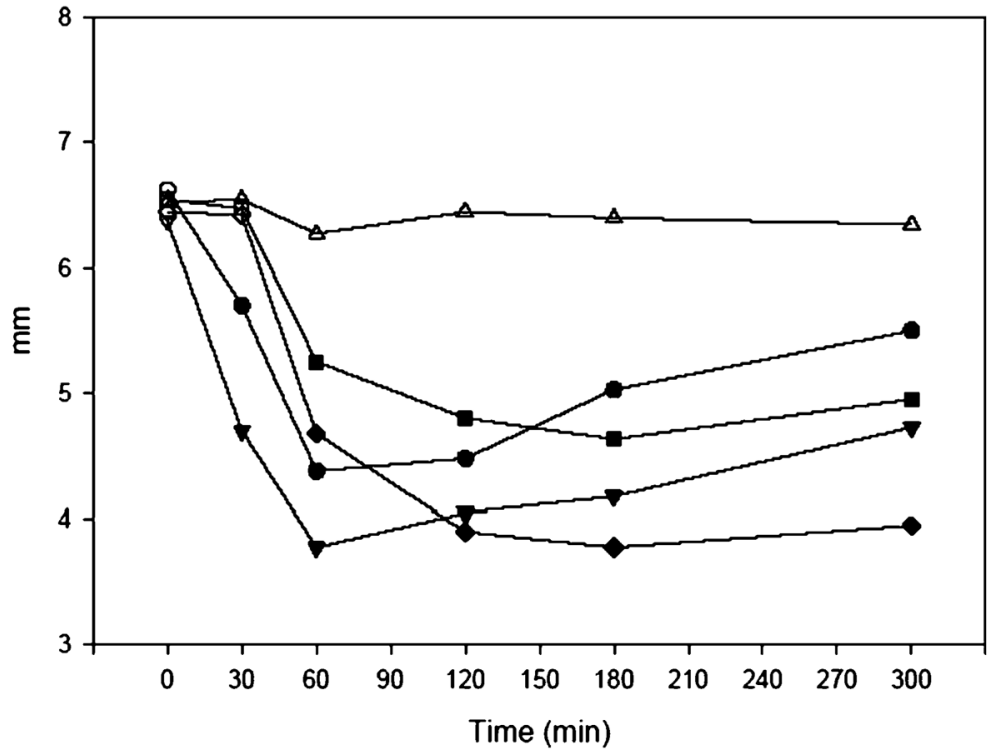

Fig 1.

Time course of the effects of oxycodone $10 \mathrm{mg}$ (circle) and $20 \mathrm{mg}$ (inverted triangle), morphine $30 \mathrm{mg}$ (square) and $60 \mathrm{mg}$ (diamond), and placebo (triangle) on "feel drug effect" ratings from the DEL/TA (a) and pupil size (b). Each point represents 20 subjects (a) or 19 subjects (b; subject 7 excluded because two pictures could not be scored). Solid symbols on the graph indicate that an active dose of the drug is significantly different from placebo at a given time point (Tukey post hoc test; $p<0.05$ ) 


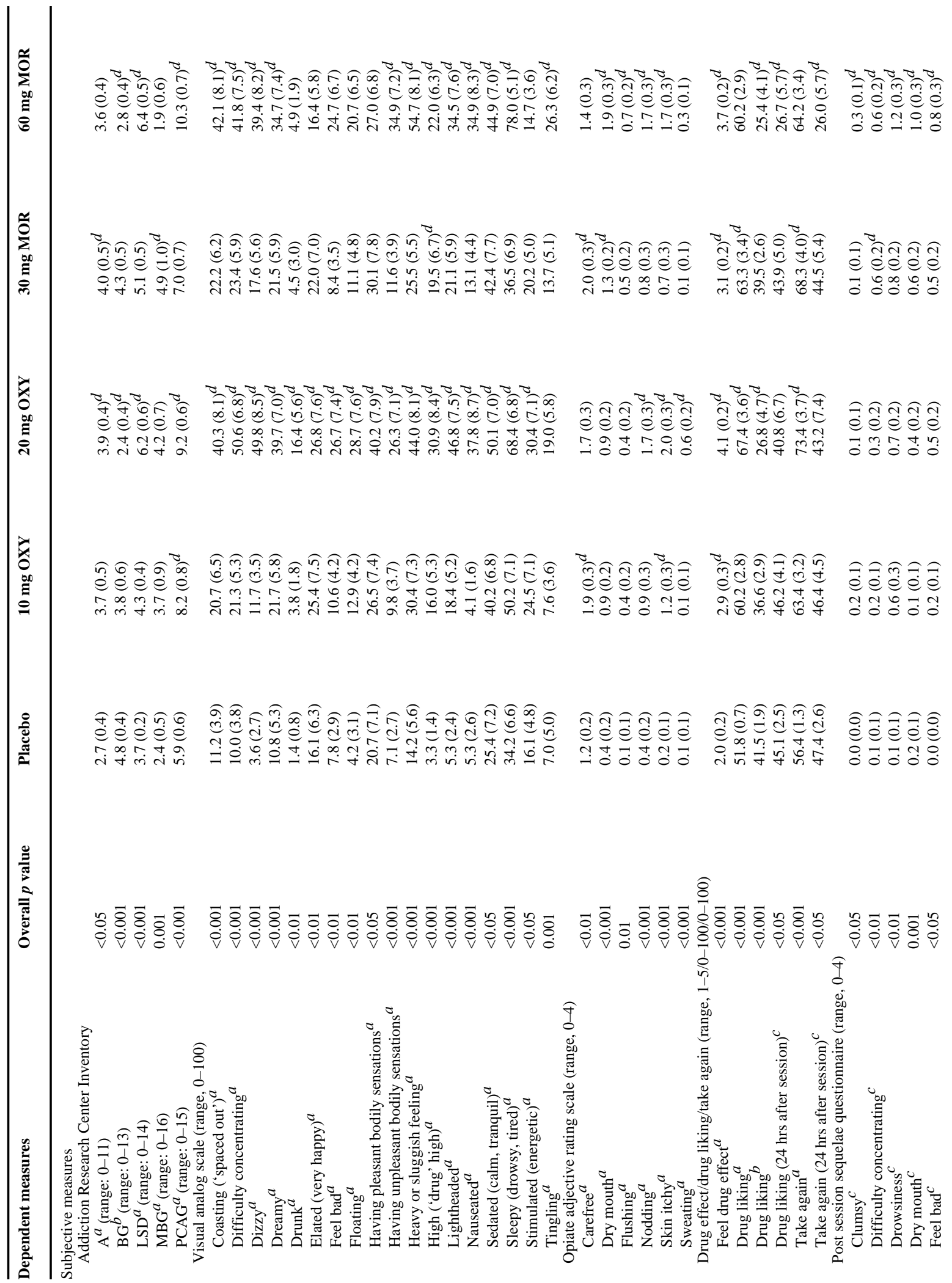




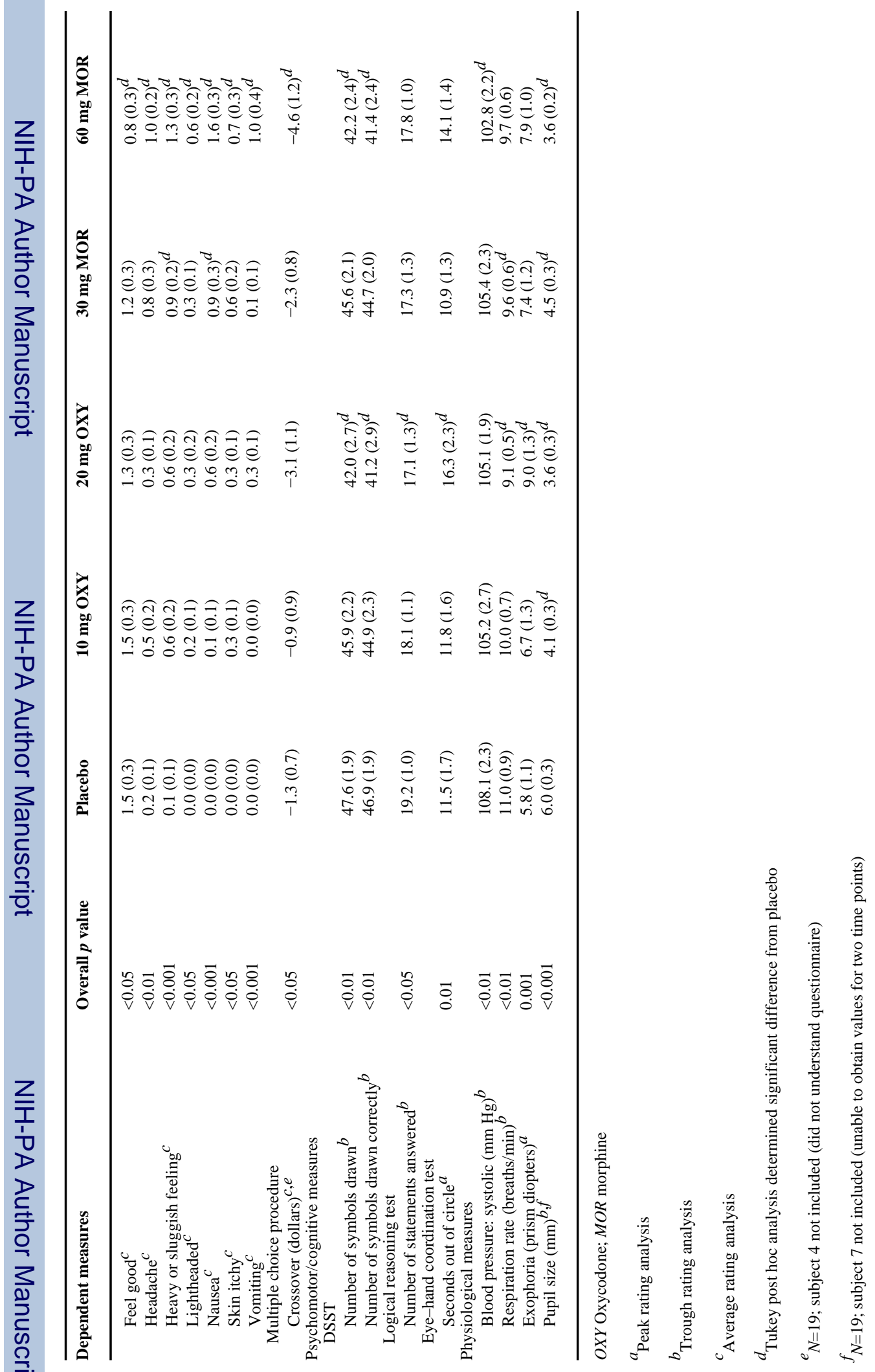


Table 2

Relative potency expressed as milligrams of morphine necessary to produce the same effect as $1 \mathrm{mg}$ oxycodone of all measures satisfying criteria for valid bioassay

\begin{tabular}{|c|c|c|}
\hline Dependent measures & Relative potency & Confidence interval \\
\hline \multicolumn{3}{|l|}{ Subjective measures } \\
\hline $\mathrm{BG}^{a}$ & 3.75 & $3.01-4.90$ \\
\hline $\operatorname{LSD}^{b}$ & 2.42 & $1.67-3.21$ \\
\hline \multicolumn{3}{|l|}{ Visual analog scale } \\
\hline Coasting ('spaced out') ${ }^{b}$ & 2.83 & $1.69-4.48$ \\
\hline Difficulty concentrating $b$ & 3.31 & $2.33-4.97$ \\
\hline $\operatorname{Dizzy}^{b}$ & 3.16 & $2.25-4.56$ \\
\hline Dreamy $b$ & 3.37 & $2.09-6.24$ \\
\hline Feel bad $b$ & 3.28 & $2.26-5.06$ \\
\hline Floating $b$ & 3.93 & $2.14-17.17$ \\
\hline Having unpleasant bodily sensations $b$ & 2.51 & $1.53-3.62$ \\
\hline Heavy or sluggish feeling $b$ & 2.73 & $1.47-4.51$ \\
\hline High ('drug' high) ${ }^{b}$ & 3.73 & $2.14-10.26$ \\
\hline Lightheaded $b$ & 3.52 & $2.30-6.30$ \\
\hline Nauseated ${ }^{b}$ & 2.78 & $1.75-4.15$ \\
\hline Sleepy (drowsy, tired) ${ }^{b}$ & 3.14 & $2.31-4.36$ \\
\hline Tingling $b$ & 2.04 & $0.35-3.57$ \\
\hline \multicolumn{3}{|l|}{ Opiate Adjective Rating Scale } \\
\hline Carefree ${ }^{b}$ & 2.52 & $0-10.63$ \\
\hline Nodding $b$ & 3.12 & $1.98-5.10$ \\
\hline Sweating $b$ & 4.04 & $2.61-9.01$ \\
\hline \multicolumn{3}{|l|}{ Drug effect/drug liking/take again } \\
\hline Feel drug effect ${ }^{b}$ & 3.31 & $2.57-4.39$ \\
\hline Drug liking $a$ & 3.14 & $2.27-4.44$ \\
\hline Take again ${ }^{a}$ & 3.33 & $2.25-5.35$ \\
\hline \multicolumn{3}{|l|}{ Psychomotor/cognitive measures } \\
\hline \multicolumn{3}{|l|}{ DSST } \\
\hline Number of symbols drawn ${ }^{a}$ & 2.97 & $1.87-4.69$ \\
\hline Number of symbols drawn correctly ${ }^{a}$ & 3.02 & $1.88-4.87$ \\
\hline \multicolumn{3}{|l|}{ Eye-hand coordination test } \\
\hline Seconds out of circle ${ }^{b}$ & 3.98 & $2.89-6.36$ \\
\hline \multicolumn{3}{|l|}{ Physiological measures } \\
\hline Pupil size $(\mathrm{mm})^{a, c}$ & 3.51 & $2.68-4.87$ \\
\hline Mean relative potency & 3.14 & \\
\hline
\end{tabular}

$a_{\text {Trough rating analysis }}$

${ }^{b}$ Peak rating analysis

${ }_{N=19 ;}^{c}$ subject 7 not included (unable to obtain values for two time points) 